\title{
Anababaların Çocuklarıyla İlgili Sosyal Medya Paylaşımları
}

\begin{tabular}{cccc}
\hline MAKALE TÜRÜ & $\begin{array}{c}\text { Başvuru Tarihi } \\
\text { Derleme Makalesi }\end{array}$ & $\begin{array}{c}\text { Kabul Tarihi } \\
11.08 .2021\end{array}$ & $\begin{array}{c}\text { Yayım Tarihi } \\
26.08 .2021\end{array}$ \\
\hline Tuba Özgül iD ${ }^{1}$, Sühendan Er iD ${ }^{2}$ ve N. Hazal Yılmaztürk iD ${ }^{3}$ \\
TED Üniversitesi
\end{tabular}

Figen Çok

Başkent Üniversitesi

\section{Öz}

Sosyal medya ortamlarına her geçen gün biraz daha fazla kişi katılmaktadır. Dünyada ve Türkiye'de henüz yeni bir konu olan anababaların sosyal medyada çocukları ile ilgili yaptıkları paylaşımlar konusuna ilişkin sınırlı bilgi birikimi bu çalışmada derlenmeye çalışılmıştır. Çalışmada günümüzde oldukça yaygın duruma gelen anababaların çocuklarına ait bilgilerin, fotoğrafların veya videoların sosyal medyada paylaşılması, anababaların çocuklarıyla ilgili neler paylaştıkları ve bu paylaşımların olası nedenleri duygu, düşünce ve davranışların başkalarına yansıtılması olgusunu kapsayacak şekilde ele alınmıștır. Paylaşımların doğum öncesinden başladığı örneklerden yola çıkarak anababaların paylaşım yaparken nelere dikkat etmeleri gerektiği ve paylaşımlar konusunda yerine getirmeleri gereken sorumluluklar vurgulanmıştır. Ayrıca konu kapsamındaki dijital ayak izi, dijital kaçırılma gibi kavramlar açıklanmış, konunun çocuk ve ergen açısından hem gelişimsel hem de çocuk hakları açısından sakıncaları tartışılmıştır. Son olarak anababaların sosyal medyada çocuklarıyla ilgili paylaşım yaparken olası tehlikler karşısında farkındalık kazanmaları için yapılabilecekler konusunda öneriler sunulmuştur.

Anahtar sözcükler: Anababalar, çocuk, çocuk hakları, ergen, sosyal medya paylaşımı.

Etik kurul kararı: Bu araştırma, derleme türünde bir çalışma olduğundan etik kurul kararı gerektirmemektedir.

\footnotetext{
${ }^{1}$ Sorumlu Yazar: Arş. Gör., Eğitim Fakültesi, Temel Eğitim Bölümü, Okul Öncesi Eğitimi Anabilim Dalı, e-posta: tuba.ozgul@tedu.edu.tr, https://orcid.org/0000-0002-7728-4334

${ }^{2}$ Doç. Dr., Eğitim Fakültesi, Temel Eğitim Bölümü, Okul Öncesi Eğitimi Anabilim Dalı, e-posta: suhendan.er@ tedu.edu.tr, https://orcid.org/0000-0002-0317-2356

${ }^{3}$ Arş. Gör., Eğitim Fakültesi, Eğitim Bilimleri Bölüm, Psikolojik Danışmanlık ve Rehberlik Anabilim Dalı, e-posta: hazal.yilmazturk@tedu.edu.tr, https://orcid.org/0000-0002-8500-518X

${ }^{4}$ Prof. Dr., Eğitim Fakültesi, Eğitim Bilimleri Bölümü, Psikolojik Danışmanlık ve Rehberlik Anabilim Dalı, e-posta: figencok@ baskent.edu.tr, https://orcid.org/0000-0003-2406-1345
} 
Hızla insanların yaşamına giren ve yaşamın akışı içinde önemli bir alışkanlık, bilgi edinme ve iletişim aracı olan sosyal medya paylaşımları, insanlar üzerinde büyük etkiler yaratarak bilimsel çalışmalar kapsamında yeni kavramların ortaya çıkmasına neden olmuştur. Bunlar arasında anababaların çocuklarıyla ilgili sosyal medya paylaşımları sharenting kavramı, İngilizce'de paylaşma share ve anababalı parenting kavramlarının bir araya gelmesiyle ortaya çıkan kavram, giderek daha fazla ve ayrıntılı biçimde anababaların her yaştaki çocuklarına ait paylaşmalarına dikkat çekmek amacıyla ileri sürülmüştür. Brosch (2019) yapılan çalışmalar 1şı̆̆ında söz konusu kavramı anababaların çocukarının mahremiyetine zarar verecek ve onlar hakkında pek çok ayrıntılı bilgiyi fotoğraf, video veya durumlarına ait gönderiler yoluyla sosyal medyada paylaşmaları olarak tanımlar.

Teknolojideki hızlı ilerleyișe ayak uydurma çabası içinde olan anababalar hamilelik döneminden itibaren, çocuklarının doğumu, büyümeleri, gelişmeleri, eğitimleri, güzel anları vb. ile ilgili bilgileri arşivlemeye başlarlar (Altun, 2019). Anababalar sosyal medya uygulamaları ile bu veriyi çok büyük kitlelere ulaştırabilmektedirler. Brosch (2016) Polonyalı anababalar ile yürüttüğü çalışmasında anababaların sosyal medyada çocuklarının fotoğraf ve videolarını paylaşma nedenleri olarak çocuklarının gelişim ve öğrenme anlarıyla ilgili yaşadıkları heyecanı, mutluluğu belirtme isteği duyduklarını ortaya koymuştur. Estonya'da yapılan çevrimiçi bir araştırma sonucunda anababaların çocuklarının görsellerini sosyal medyada paylaşmalarının nedeninin akrabaları ve yakın arkadaşları ile iletişim içinde olma isteği olduğu görülmüştür (Sukk ve Soo, 2018). Benzer şekilde, Duggan ve diğ. (2015), çocuklarının büyüme süreçlerine akrabaları ve yakın arkadaşları dâhil etme isteğinden dolayı anababaların sosyal medyada çocuklarının fotoğraf ve videolarını paylaştıklarını belirtmişlerdir. Sosyal medya platformları aile özelinin ve olaylarının sergilendiği bir sahne durumunu almıştır (Lazard ve diğ., 2019). Ouvrein ve Verswijvel (2019) bu paylaşımları, anababaların ebeveyn olarak yeterliklerini çevrimiçi ortamlarda sergileyebilecekleri bir çeşit dolaylı kendini gösterme aracı olarak tanımlamaktadır.

Anababaların çocuklarını ve çocuklarının bilgilerini sosyal medyada paylaşımları sadece fotoğraf ya da video paylaşımı biçiminde değildir. $\mathrm{Bu}$ paylaşımların içeriğinde çocuk büyütme, çocuk gelişimi ve eğitimi gibi çeşitli bilgiler ve öneriler de yer almaktadır. Aslında anababalar aynı zamanda başkalarının paylaşımlarını izlemekte ve bu paylaşımlardan çocuk bakımı, eğitimi, gelişimi gibi konularla ilgili çok şey öğrenmektedirler (Steinberg, 2017). Paylaşımların izlenmesi, diğer anababalardan gelecek olan öneriler, arkadaşlar ve akrabalarla bağlantı içinde olma isteği anababaların çocuklarıyla ilgili paylaşım yapmaları konusunda güdülenme (motivasyon) yaratmaktadır (Bessant, 2018). Diğer bir deyişle, hem paylaşma hem de paylaşımlardan öğrenme açısından sosyal medyada yer alan anababa gönderileri önem taşımaktadır.

Anababaların çocuklarıyla ilgili fotoğraf ve videolarını sosyal medyada paylaşmalarını inceleyen kültürlerarası çalışmalar önem gösterse de sınırlıdır. Türk 
kültürünün bu bağlamda ele alındığı tek bir çalışma yer almaktadır. Türk ve İngiliz annelerinin çocuklarıyla ilgili fotoğraf ve videdolarını sosyal medyada paylaşmalarını inceleyen bu çalışmada, iki kültür arasında farklılıklar söz konusu olsa da teknolojinin dinamiklerine dayalı benzer temaların toplumlar ve anneler üzerinde benzer etkilere sahip olduğu belirtilmiştir. Örneğin, Türk ve İngiliz anneler, neredeyse tüm yapılan paylaşımlarına olumlu (pozitif) yorumlar yapıldığını ve bunların kendilerini ve çocuklarını mutlu ettiğini belirterek, bu durumun paylaşımlarına devam etmeleri konusunda güdülenme kaynağı olduğunu belirtmişlerdir (Günüç, 2020).

Anababaların sosyal medyada çocuklarıyla ilgili paylaşımları daha bebek ana karnındayken başlayıp ergenlik yaşlarına kadar hatta yetişkinlikte de devam etmektedir. Ancak bu paylaşımlar yapılırken etik ve ahlaki ilkeler genellikle anababalar tarafından dikkate alınmamaktadır (Archer ve Kao, 2018; Bessant, 2018; Moser ve diğ., 2017). Anne adayları ultrason görüntülerini ve olası doğum zamanını sosyal medya üzerinden paylaşmakta iken bazı anneler doğmamış çocukları için hesap açıp bu hesaplara doğacak çocuklarının ismini verip çok sayıda izleyici (takipçi) edinebilmektedir (Abidin, 2015; Morse, 2019).

Kumar ve diğg. (2019) göre anababaların çocuklarının fotoğraf ve videolarını sosyal medyada paylaşmaları aslında yaşama yeni girmiş bir olgu değildir. Yüzyıllardır anababaların çocuklarına ait bilgi ve anı toplama ile paylaşma yönünde bebek ve çocuk günlükleri tutma, fotoğraf albümleri düzenleme gibi çocuklara ait paylaşımlar konusunda benzer örnek davranışlar bulunmaktadır. Ayrıca anababaların çocukları ile ilgili konuları sohbetlerine ne kadar çok taşıdıkları, evlerinde çocuklarına ait fotoğrafları her zaman başköşelerde tuttukları bilinmektedir. Yani sosyal medya öncesinde de çocuklara ait paylaşımlar çeşitli şekillerde her zaman anababaların gündeminde ve yaşamında olmuştur. Bu nedenle toplumun inşasında da bir araç olarak kullanılan anababaların çocuklarıyla ilgili sosyal medya paylaşımlarında kültür ve değerlerin etkili olduğu göz önünde bulundurulmalıdır (Benevento, 2018). Humphreys (2018) sosyal medyada bu tür bilgilerin paylaşılmasının, paylaşanların kişilikleri ve kimlikleri için önemli hale geldiğini vurgulamıştır. Artık günümüzde sosyal medya paylaşımları kapsamında anababaların çocuklarına ait paylaşımlarının neredeyse günlük yapılması gereken bir iş durumuna geldiği bile söylenebilir.

\section{Anababaların Çocuklarının Fotoğraf ve Videolarını Sosyal Medyada Paylaşma Güdülenmeleri}

Çok çeşitli araştırmalarda anababaların neden ya da hangi güdülenmeyle çocuklarının fotoğraf ve videolarını sosyal medyada paylaşmalarına ait açıklamalar görülmektedir. İleri sürülen bazı paylaşım nedenleri aşağıda kısaca açıklanmaktadır.

\section{Benlik Sunumu}

Sosyal medya insanlar arasında ilişki kurulmasını sağlayan değerli bir araçtır. $\mathrm{Bu}$ yolla insanlar kendilerini göstermenin yolunu saptamışlardır. Kişiler kendi fotoğraflarını paylaşarak kendilerine özgü özellikleri gözler önüne sermekte ve benzer durumu çocuklarının fotoğrafları üzerinden uygulayıp beğeni veya yorum alarak 
sosyal doyum (tatmin) sağlamaktadırlar. Goffman'ın (1959) Benlik Sunumu Kuramı, kişinin kendini göstermek istediği şekilde, kimi zaman olduğundan farklı olarak, kendini karşı tarafa sunması üzerine kuruludur. Oldukça köklü bir kuramsal bakış açısına dayanan bu yaklaşım, insanların kendilerini başkalarının görmesini istediği biçimde sunma çabası anlayışına dayanmaktadır. Bu çaba günümüzde sosyal medya paylaşımlarının değerlendirilmesi açısından da önem taşımaktadır (akt., Albayrak, 2019).

Goffman (1959) kişinin başkalarıyla karşılaşması durumunda kendisini nasıl yeniden ele aldığını, nasıl yeni bir şekilde sunduğunu ve bunun için nasıl yeni stratejiler gerçekleştirdiğini benlik sunumu kavramını kullanarak açıklar. Goffman benliği performans sırasında sergilenen bir görüntü olarak tiyatro metaforuyla ele alır. Bu bağlamda iki benlik kavramından ilki olan oyuncu benlik, bireyin bir aktör olarak rolünü oynarken ilettiği benliktir. $\mathrm{Bu}$ benlik türünde ideal benlik için çabalanır. İletilmek istenen benlik aktörün elindedir ve karşısındaki insanlara göre değişmektedir. İkinci benlik kavramı olarak tanımlanan uzlaşımsal benlik, tiyatro oyunu sırasında izleyicinin müdahalesinin olduğu hem aktöre hem de izleyiciye hitap eden benliktir. İletişimde bulunulan her insana göre değişen performanslar sergilemek gerçek bir benliğin oluşmasını zorlaştırmaktadır (akt., Albayrak, 2019). Buna koşut (paralel) olarak anababaların sosyal medya platformunda çoğunlukla olumlu paylaşımlar yapmaları (Maraşlı ve diğ., 2016), iletmek istedikleri örüntüleri sergilemeleri çerçevesinde ele alınabilir. Öte yandan anababalar, söz gelimi sahnede çocuklarına karşı olan ilgilerini sergilemek için de onlarla ilgili sosyal medya paylaşımları yapmaktadırlar (De Wolf, 2020). Anababaların çocuklarının fotoğraf veya hikâyelerini paylaşımları ise iyi ve sevgi dolu ebeveynlik tablosu çizdiklerini göstermenin bir yolu olarak düşünülmektedir.

\section{İletişim}

Bir çalışmada anababaların çocukları ile iletişim kurmak için sosyal medya kullanmayı, mesajlaşmak ya da Skype gibi araçlara başvurmaktan daha sık tercih ettiklerini ortaya konulmuştur. Bununla birlikte, ergenlik döneminde çocuğu olan anababaların sıklıkla sosyal medya üzerinden çocukları ile iletişime geçtiği ve iletişim amaçlı teknoloji kullanımına oldukça olumlu yaklaştıkları bilinmektedir (Doty ve Dworkin, 2014). Ergenlik döneminde, bireylerin kendilerini anababalarına açma davranışının azalması, anababaları bu şekilde çocukları ile iletişimi korumaya yöneltmektedir (Hessel ve diğ., 2017). Ayrıca anababaların çocuklarla ilgili etkinlikler hakkında bilgi alışverişi yapmak ve iletişimde kalmak için de paylaşım yaptıkları görülmektedir (Latipah ve diğ., 2020).

\section{Sosyal Destek ve Anababalık Deneyimi}

Yeni doğum yapmış anneler için anne olarak özgüven kazanmak ve teknoloji kanalını kullanarak yeni rollerine ilişkin ortamlar yaratmak önemli olabilmektedir. Anne olmanın ötesinde bu tür sosyal medya ortamları özellikle yeni bebek nedeniyle değişen yaşamlarında onların dış dünya ile iletişiminin kopmamasının yolunu 
açmakta ve çocuklarının beslenmelerinden çocuk eğitimine dair oyun/ kitap/ yaratıcı etkinlik öneriyle ilgili paylaşımlar yaparak, tepkiler ve beğeniler alarak bir çeşit destek işlevi sağlamaktadır (Başoğlu, 2020; Gibson ve Hanson, 2013). Nitel bir çalışmada bu gereksinim, katılımcı anneler tarafından açıkça belirtilmiş ve sosyal medya paylaşımlarının bu gereksinimi gidermeye hizmet ettiğine değinilmiştir (Latipah ve diğ., 2020). Tüm yaş grupları için anababaların çocuklara ait paylaşımlarda bulunmaları benzer şekilde sosyal destek sağlamaktadır.

Bugünün anababaları, çocukları ile ilgili paylaşım ortamı olarak sosyal medyayı kullanmayı, bir çeşit anababalık deneyimi olarak görmektedirler (Archer ve Kao, 2018). Sosyal medya kişiler arasında iletişimin, anababalarla ve arkadaşlarla yapılan paylaşımların yolunu açmıştır. Yapılan paylaşımlar bir anda pek çok kişiye ulaşmakta ve anababaların aralarında iletişimin bile olmadığı kişilere bu paylaşımlar aktarılmaktadır (Aslan ve Durmuş, 2020). Bu paylaşımlara gelen yorumlar, anababaları yeni deneyimler için güdülemekle birlikte, beğenilme gereksinimlerini çocukları aracılığıyla karşılamalarına da dayanak oluşturmaktadır (Günüç, 2020; Latipah ve diğ., 2020).

\section{Arşivleme}

Anababalar çocuklarıyla geçirdikleri vakitleri ve anıları arşivlemek ve sonrasında tekrar bakabilmek adına da sosyal medyada paylaşım yapabilmektedirler. Anababalar bu tür paylaşımların arkasındaki bir diğer nedenin, çocuklarının büyüdüklerinde geçmişe dönük anıları görebilmelerini sağlamak olduğunu belirtmektedirler. Arşivlemenin bir diğer nedeninin ise anababaların çocuklarının motor ve psikososyal gelişimlerini fotoğraf ve videolarla kayıt altına alıp gelişim dönemine uygunluğunu takip etmek ve değerlendirmek olduğu bilinmektedir (Latipah ve diğ., 2020).

\section{Sosyal Medyada Anababaların Çocuklarıyla İlgili Paylaşımlarından Fenomenliğe}

Bugün çok çeşitli özellikleriyle dikkat çeken sosyal medya fenomenliği bir sosyal olgu olarak karşımıza çıkmaktadır. Sosyal medyadaki uygulamalarda kullanıcılara hitap eden fenomenlerin bazıları sosyal medya ya da televizyon dünyasına da giriş yaparak çeşitli roller üstlenebilmekte yorumculuk, şarkıcılık, gurmelik, moda gibi çeşitli alanlarda da hünerlerini sergilemektedir. Konuya ilişkin dikkat çeken nokta, çocukların anababaları tarafından sosyal medya fenomenliğine taşınmasıdır (Benevento, 2018).

Konuya ilişkin dikkat çeken nokta, çocukların anababaları tarafından sosyal medya fenomenliğine taşınmasıdır. Bu olguya bir örnek olarak günümüzde dünyada 3.5 milyon kadar izleyicisi olan Çocuk Modası Instagram hesabı ve etiketi (fashionkids) kendini tüm dünyadan çocuk modasını, tasarımını ve yaşam stilini dikkatlice kurgulayan ilham verici anababaların platformu olarak tanımlamaktadır (Benevento, 2018). Daha çok 0-6 yaş arası şık çocuk fotoğraf ve görüntülerinin anababalar tarafından paylaşıldığı bu hesapta satış hedefi de bulunmaktadır. Dünyanın 
pek çok ülkesinden anababalar çocuklarına ait giyim, çocuk odası, çocuk eşyası, çocuk ve doğa, çocuk ve hayvan, oyuncak fotoğraflamakta ya da video kaydı yapmakta ve bu hesapta paylaşmaktadır. Paylaşımlar arasında yeni doğmuş bebeklerin adları ile doğum boy ve kilo bilgileriyle paylaşıldığı örnekler bile bulunmaktadır (Erişir ve Erişir, 2018).

Günümüzde sosyal medyadaki bir diğer çocuk fenomen Kobe eats hesabı, ana babası tarafından çocuğun sürekli yemek yeme ve yemek yapma videolarının paylaşıldığı bir hesaptır. Bu hesap çok izlenilen ve çocuğun videolardaki giysilerinin ve bunlardan esinlenerek üretilmiş çeşitli ürünlerin satışına da olanak veren 2.5 milyon kadar izleyicisi olan bir hesaptır. Bu hesap da Kobe yemek pişirmeyi, yemek yemeyi ve mutfakta incelemeyi severim sloganıyla tanımlanmaktadır. Hatta Kobe hayranları olarak tanımlanan ve Kobe'nin Dünya'nın en tatlı şefi olarak anıldığı ayrı hesaplar da açılmışırı. İnternette basit bir aramayla çocuk hakkında pek çok bilgiye ulaşmanın olanaklı olduğu bu sosyal medya paylaşımları özellikle Covid-19 pandemi sürecinde hızla popüler olmuştur. Bu hesabı yöneten Kobe'nin annesi CNN International TV kanalında söz konusu hesap ve oğlu Kobe hakkında açıklamalarda bulunacak kadar önemli bir toplumsal konu oluşturmuştur. Ayrıca bu tür çeşitli hesaplarda belirtildiği gibi pek çok ticari ürün paylaşılmakta ve satışı yapılmaktadır. Örneğin, Kobe Eats yazılı kıyafetler tasarlanmıştır. Kobe'nin videolarında üzerinde bulunan aşçı şapkası ve önlüğ̈̈nün yanı sıra pek çok bebek ve çocuk giysisi aracı anababaları tarafından satışa sunulmakta ve önemli bir gelir elde edilmektedir. Yapılan araştırmalar bu örnekte olduğu gibi, anababaların çocuklarını sosyal medya kanalı ile paylaşarak ticari yarar gözettiklerine ve bu paylaşımlar aracıllğıyla büyük ölçüde ticari ürün reklamı yaptıklarına işaret etmektedir (Erişir ve Erişir, 2018).

\section{Anababaların Sosyal Medyada Çocuklarının Fotoğraf ve Videolarını Paylaşmalarının Çocuk Hakları Açısından Değerlendirilmesi}

Anababalar yaptıkları paylaşımlar ile uluslararası sözleşme ve yasalarla belirlenmiş çocuk haklarını önemli ölçüde göz ardı etmektedirler (Serin, 2019). Çocukların temel olarak her türlü ihmal, istismar ve riskten korunması temel haklarından biridir. Türkiye dahil toplam 196 ülkenin taraf olduğu Birleşmiş Milletler Çocuk Haklarına İlişskin Sözleşme'nin ilk maddesinde 18 yaşından küçük her bireyi çocuk olarak nitelendirmiş, diğer 53 madde ile çocuk haklarını ayrı ayrı belirtmiş ve sınırlarını çizmiştir (Lynch ve Liefaard, 2020). Sözü edilen çocuk haklarına dair sözleşmedeki çocuk haklarına yönelik maddelerin çoğu çocukların fotoğraf ve videolarının anababaları tarafından sosyal medyada paylaşılması ile ilişkilendirilebilir. Sözleşmenin 12. Maddesi'nde çocuğun kendisini ilgilendiren her türlü konuda kendi görüşlerini özgürce ifade etme, görüşlerine önem verilmesini isteme hakkına sahip oldukları belirtilmiştir. 16. Maddesi'nde onurlu ve saygılı bir yaşam sürecekleri şekilde küçük düşürülmeden ve özel yaşamlarına müdahale edilmeden yaşama hakkına sahip oldukları belirtilirken 19. Maddesi'nde ise bakımı ile ilgilenen kişilerin yetki ve sorumluluklarını çocuğa zarar verecek şekilde kullanamayacakları açıkça vurgulanmıştır. Ayrıca 19. Madde'de çocuklar için zararlı olabilecek durumlar için yasal, yönetsel, toplumsal ve eğitsel tüm önlemlerin alınması 
gerekliliği vurgulanmıştır. (Birleşmiş Milletler Çocuklara Yardım Fonu [UNICEF], 1989; Türkiye Büyük Millet Meclisi [TBMM], 2016). Bu maddeler doğrultusunda anababaların, çocuklarının fotoğraf ve videolarını izin almadan sosyal medyada paylaşmaları ve onları tehlikeli durumlara düşürebilecek bu alışkanlıkları ile Birleşmiş Milletler Çocuk Haklarına İlişkin Sözleşme'yi ihlal ettikleri söylenebilir.

Benzer şekilde Avrupa İnsan Hakları Sözleşmesi'nin 8. Maddesi, çocukların özel yaşamlarının korunması ve özel yaşamlarına saygı duyulması ile ilgilidir (Avrupa Konseyi [CE], 1950). Aynı zamanda Türkiye Cumhuriyeti Anayasası, çocuk haklarını bu bağlamda kapsamakta ve güvence altına almaktadır. Anayasa'ya göre anababalar, eğitim ortakları ve devletler, çocukları her türlü riskten korumak için önlemlerini almalıdır. Bu önlemler doğrultusunda, Milli Eğitim Bakanlığı (MEB) 2017 yılında yayınladığı 2017/12 sayılı Okullarda Sosyal Medya Kullanımı adlı genelgede okul ortamında öğrencilere ait fotoğraf ve videoların sosyal medyada paylaşılmasının yasak olduğunu ve ihlal edenler hakkında yasal işlemler ile paylaşımların önüne geçileceğini belirtmiştir (MEB, 2017). Ancak unutulmaması gereken esas nokta birincil sorumluluğun anababaların üzerinde olduğu ve anababaların bu sorumluluğu yerine getirmediği durumda, çocuğun yüksek yararını gözetmek için devletin devreye girmesinin beklenmesidir (Kurt, 2016).

Anababaların çocuklarını korumaları doğal bir beklenti iken, onların sosyal medyada yaptıkları paylaşımlarla yalnızca kendi yaşamlarına ilişkin değil çocuklarının kişisel bilgilerini ve onların mahremiyet niteliği taşıyan deneyim ve özelliklerini de paylaşmakta oldukları söylenebilir (Steinberg, 2017). Bu paylaşımlarla çocuklarının gizliliğini ihlal ederek dikkat çekmeye çalışan ve bunun üzerinden bir çıkar (ün, para vb.) elden eden anababalar hakkında açılmış davalar bulunmakadır (Kopecky ve diğ., 2020). 2015 yılında ABD'deki Çevrim İçi Aile Güvenliği Enstitüsü'nün (FOSI) çocuklarla yürüttüğü bir çalışma sonucunda çocukların rızası alınmadan yapılan sosyal medya paylaşımlarının oldukça fazla olduğu görülmüştür. Çocukların rızası olmayan paylaşımlar hakkında anababalarına dava açabilme yetkisi için düzenlemeler son yıllarda çoğu Avrupa ülkesi ve Amerika Birleşik Devletleri tarafindan gündeme getirilmektedir (Bessant, 2018). Örneğin, Amerika Birleşik Devletleri'nde yaşayan bir anababa, 9 ve 11 yaşlarındaki çocuklarını fiziksel ve duygusal olarak istismar ettikleri ve çocuklarına ait çı̆̆lık ve ağlamalarını içeren videoyu dünyanın en çok izlenen video paylaşım platformlarından birinde izleyicileriyle paylaştıkları için dünya gündeminde konu olmuşlardır. Yüz binlerce izleyiciye ulaşan bu videodan sonra, mahkeme anababanın çocuklarını istismar ettiklerine karar vermiş ve anababayı beş yıl hapis cezası ile yargılamıştır (Kopecky ve diğ., 2020).

Benzer şekilde, Türkiye'de Türk Ceza Kanunu'nda özel yaşamın gizliliği ilkesi benimsenmiş ve mevcut yasalar ile çocukların yetişkinlik çağına geldiklerinde anababalarına karşı davacı olmalarının önünü açmıştır (TBMM, 2004). Ülkemizde çocukların fotoğraf ve videolarının sosyal medyada paylaşılmaları ile ilgili emsal bir karar oluşturan ve 2017 yılında açılan davada, çocukları üzerinden yaptı̆̆ 
paylaşımlarla ünlü olan bir anneye, baba tarafindan dava açılmıştır. Davacı baba, bu paylaşımlarla çocuklarının özel yaşamının ihlal edilerek reklam amacıyla anneleri tarafından istismar edildiğini bildirmiş̧ir. Bu davada mahkeme babayı haklı bulmuş, annenin sosyal medya paylaşımlarında bulunmasını yasaklamış ve çocukların velayetini babaya vermiştir (Dönmez, 2019).

Yapılan araştırmalarda, büyüdükçe kendisi hakkında yapılan paylaşımların farkına varan çocukların, anababalarının kendilerini çıplak, utanç verici hallerle paylaşımlarından çoğunlukla hoşnut olmadıkları ve anababa ile çocuk arasındaki güven ilişkisinin kötü etkilendiği gözlemlenmiştir (Haley, 2020). Son yıllarda internet paylaşımları hakkında davaların artışı ile yeni bir temel hak olarak önerilen Unutulma Hakkı (Right to be Forgotten) konusu da gündeme gelmiştir. Unutulma Hakkı bireyin kendisi hakkında internet ortamında hiçbir belge ya da fotoğrafin yer almamasını isteme ve silinmesini isteme hakkı olarak tanımlanmaktadır (Nalbantoğlu, 2018). Bu tanımdan anlaşılacağı üzere anababaları tarafından kişisel bilgi, fotoğraf ve videoları paylaşılan çocuklar, bu paylaşımların dijital ortamdan yok edilmesini isteme hakkına sahiptir. Bu bilgiler ışığında, konunun çocuklar açısından ciddi bir hak ihlali doğurduğu ortaya konulmuş ve çocuklara haklarını arama firsatları sunulduğuna dikkat çekilmiştir.

\section{Dijital Ayak İzi ve Dijital Kaçırılma}

Anababaların çocuklarını sosyal medyada paylaşmalarının beraberinde getirdiği önemli kavramlar arasında dijital ayak izi ve dijital kaçırılma yer almaktadır. Bu kavramlar özellikle anababaların çocuklarına ait sosyal medya paylaşımlarının çocuk istismarı ile ilişkisini ön plana çıkarmaktadır. Anababalar herhangi bir kasıt gözeterek veya gözetmeyerek sosyal medyada yaptıkları paylaşımla çocuklarına ait dijital ayak izi oluşturmaktadırlar. Anababaların çocuğu ile ilgili yaptığı paylaşımlar çocuğun dijital ortamda ayak izinin belirlenmesi olarak tanımlanmaktadır. Çocuklar doğdukları andan itibaren anababaları onlara ait kişisel bilgileri paylaştığında internette sanal ayak izleri oluşmaya başlamaktadır (Cino ve Dalledonne-Vandini, 2020). Aslında anababalar paylaşım yaparken bu paylaşımın sadece kendi izleyicileri tarafından görüntüleneceğini düşünürler. Kendi seçtikleri izleyicileri ile yaptıkları paylaşımların gerçekte çok daha büyük kitlelere ulaşabileceğini hesaba katmazlar. Ancak izleyiciler bu paylaşımları saklayabilir veya benzer şekilde başkaları ile paylaşabilirler.

Sosyal medyanın en önemli isimlerinden biri Mark Zuckerberg 2012 yılında, dijital ayak izinin gelişen bir olgu olduğunu, anababaların sosyal medyada çocuklarına ait paylaşımlarının sonucu olarak çocukların dijital ayak izlerinin oluşturulmasının ve çocuklar büyürken kişisel bilgilerinin ortaya konulmasının önlenemez olduğunu söylemiştir (Zuckerberg, 2020). Dijital kaçırılma ise bir yabancının bir çocuğun görüntülerini sosyal medyadan çalması ve farklı kurgularla bu çocuğun kimliğini ya da görüntüsünü kullanmasıdır. Hatta zaman zaman çocukların bazı bireylerce kendi çocuklarıymış gibi kullanılması durumuna da rastlanmaktadır (Schroeder, 2020). Çocuklarla ilgili yapılan paylaşımlar izleyiciler tarafından da paylaşılabilmekte ve 
çocukların yaşadıkları yer gibi özel bilgilere başkaları tarafından kolaylıkla ulaşılabilmektedir (Kopecky ve diğ., 2020).

Çocuğun yaşadığı yerin ve gittiği okulun adresini sosyal medya paylaşımları yoluyla duyurmak, çocuğun görüntüsünü yayımlamak, doğum günü, sevdiği veya sevmediği şeyler hakkında paylaşımlarda bulunmak çocuklar için potansiyel dijital kaçırılma ortamı hazırlamaktadır (Whigham, 2015). Ancak anababalar bu potansiyel tehlikeyi hesaba katmamaktadır. Coughlan ve Lister (2018), İngiltere'de yayınlanan rapora dayanarak 2030 yılı itibari ile davaların üçte ikisinin anababaların çocuklarını sosyal medyada paylaşmalarından kaynaklanan çocuk kaçırılma olaylarını kapsayacağını ileri sürmektedir. Görünen o ki, çocukla ilgili yapılan paylaşımlar giderek artan ölçüde kaydedilip saklanabilecek ve istismarcılar ellerinde tuttukları bilgiyi kullanarak sahte hesap açabilecek ve farklı şekillerde çocukların istismar edilmesi yaygınlaşacaktır.

\section{Dijital Kaçırılma Örneği: Bebek Rol Canlandırması (Baby Role Play)}

Anababalar sosyal medyada çocuklarını teşhir eden fotoğraflar paylaşırken fotoğrafların art niyetli kişiler tarafından ele geçirilip farklı hesaplar altında kullanılabileceğini göz ardı etmemelidir. Sosyal medya gibi çevrimiçi platformlarda, kullanıcılar oyun oynamak gibi farklı amaçlarla başkalarının kimliklerine bürünebilmektedir. Bu amaçla, kişiler tanınan bir insanın kimliğine bürünüp onun gibi davranmakta ve diğer insanlara kendini ünlü kişiymiş gibi tanıtabilmekte ve hatta onun adına söylemlerde bulunabilmektedir. Bu tür farklı kimlikler ile sosyal medyada var olmaya canlandırma (role-play) ismi verilmektedir. Kullanıcılar kendilerini oyuncu (player) olarak tanımlamaktadır. Bu canlandırmaların en tehlikeli biçimi ise anababaları tarafindan sıkça fotoğraf ve videoları paylaşılan bebek ve çocukların kullanılmasıdır. Oyuncular başkalarının çocuklarını kendi çocukları gibi düşünebilmekte ve sanki çocukların öz anababaları gibi paylaşımlarda bulunmaktadırlar. Alanyazında sanal evlat edinme (virtual adaption) olarak geçen bu kavram açık bir dijital kaçırılma örneğidir (Sullivan, 2019). Instagram'da sıklıkla kullanılan \#bebekrolyapma (\#babyroleplaying) ve \#babyrp hashtagleri ve ayn isimlerle açılan çok sayıda kullanıcı hesabı bu dijital kaçırılmayı gözler önüne sermektedir (Lumsden, 2014). Bu hesapların sahipleri olan tehlikeli kişiler gerçek isimlerini kullanmadan kendilerini canlandırma oyuncusu (role-player) olarak tanımlamakta ve bebek fotoğraflarını paylaşırken aynı zamanda ticaret yaparak gelir sağlamaktadırlar. Kendi aralarında birbirlerine karşı kurdukları sanal bir bağ ile sahte hesaplar açarak anababaları tarafından sosyal medyada paylaşılan bebekleri -kendi deyimleri ile sahiplenmektedirler. Sahiplendikleri bebeklerin fotoğraf ve videolarını açmış oldukları sahte hesaplarda sanki kendi çocuklarıymış gibi paylaşmaktadırlar (Schroeder, 2020). Ebeveynlerin sosyal medyada çocuklarına ilişkin paylaşım yaparken en fazla çocuklarının görünüşüne ve mahremiyetine dikkat ettiklerini öne süren çalışmalar olsa da ilgili paylaşımların devam etmesi kimi zaman riskli sonuçlara neden olabilmektedir (Akpınar ve diğ., 2020; İnan-Kaya ve Kaya, 2017; Turgut ve diğ., 2021). Bebeklerin fotoğraf ve videoları kullanılarak dijital kaçırılmaya dur 
demek için \#fotoğrafçalımınıdurdur (\#stopstealingpics), \#bebekrolyapmayıdurdur (\#stopbabyrp) gibi hashtaglerle konu gündeme gelse de anababalar, dijital kaçırılmanın ve olası zararlarının farkında olmadan çocuklarının gizliliğini ve güvenliğini göz ardı eden sosyal medya paylaşımlarına devam etmektedirler (Lumsden, 2014).

Ergenler Açısından Anababaların Sosyal Medyada Fotoğraf ve Video Paylaşmalarının Önemi

Henüz yaşadığı dünyanın yeterince farkında olmayan, konuşmayı bile başaramayacak, duygularını ifade edemeyecek yaşta olan küçük bir çocuğun görüntülerinin anababaları tarafından sosyal medyada paylaşılması karşısında yapabileceği bir şey yoktur. Çünkü o yaştaki küçük çocuk zaten yapılan şeyin ne olduğunu kavrayamaz. Dahası, sahip olduğu hakların farkında bile değildir. Anababaların çocuklarının fotoğraf ve videolarını sosyal medyada paylaşmaları konusunda ergenler de risk altındadırlar. Ancak, ergenler konu ile ilgili endişelerini dile getirebilir ve anababalarının kendilerine ait fotoğraf ve videolarını paylaşmaları konusunda itirazlarını dile getirip anababalarına dava bile açabilirler (Bessant, 2018; Oswald ve diğ., 2016).

Sarkadi ve diğ. (2020) 4-15 yaş arasında 68 çocukla yaptıkları araştırmada, araştırmaya katılan çocuklar genel olarak anababalarının sosyal medyada yaptıkları paylaşımlardan memnun olmadıklarını belirtmişlerdir. Çocuklar sırasıyla en çok sosyal medyada fotoğraflarının paylaşılmasından, izinsiz fotoğraf çekilmesinden ve kendisi hakkında sosyal medyada bir şeyler yazılmasından hoşlanmadıklarını belirtmişlerdir. Diğer yandan fotoğraflarının herhangi bir yakınlarına yollanmasına daha az tepki gösterdikleri görülmüştür. İzinsiz fotoğraflarının çekilmesi küu̧ük yaştakiler için daha kabul edilebilirken çocukların yaşı büyüdükçe fotoğraflarının izin alınarak çekilmesi gerektiği görüşü yaygınlaşmıştır. Çocukların bu paylaşımlarıyla ilgili çıkarılması gereken sonuç ortadadır. Çocuklar ve ergenler anababaları sosyal medyada paylaşım yapmadan önce kendilerine sorulmasını ve görüşlerinin dikkate alınmasını istemektedirler.

Ergenler ve anababalarının onlar ile ilgili yaptıkları sosyal medya paylaşımlarıyla ilgili örüntüler çeşitlilik göstermektedir. Örneğin ergenlerin anababalarının yaptıkları paylaşımlarla ilgili utanç, rahatsızlık ve hayal kırıklıkları yaşadığını ve bu durumdan hiç memnun olmadıklarını belirten çalışmalar bulunmaktadır (Levy, 2017; Siibak, 2019). İngiltere'de 12-16 yaş arası 1,000 öğrenci ile yapılan bir çalışmada katılımcıların \%71.3'ü anababalarının mahremiyetlerine saygı göstermediklerini, \%39.8'i ise anababalarının kendilerine utanç veren, tuhaf göründükleri, tuhaf davrandıkları veya çıplak görüntülerini sosyal medyada paylaştıklarını belirtmişlerdir (Levy, 2017). İlk ergenlik dönemindeki çocuklar da sosyal medyada paylaşım yapmadan önce anababalarının kendilerini bilgilendirmelerini ve izin almaları gerektiğini vurgulamışlardır. Ne yazık ki çocuklar, anababalarından sosyal medyada yer alan kendilerine ait hoşnut olmadıkları görüntüleri kaldırmalarını istediklerinde anababalarını bu duruma tepkisiz 
kaldıklarını belirtmişlerdir. Dahası anababalar, özellikle küçük yaştaki çocuklar üzerinde, sosyal medyada istedikleri gibi paylaşım yapma hakkına sahip olduklarını dile getirmiş̧lerdir (Lipu ve Siibak, 2019). Bu noktada anababaların çocuklarını koruma davranışları ile onların mahremiyetlerini sosyal medyada paylaşmaları arasında bir ikilem olduğu söylenebilir.

Ergenler arkadaşlarının sosyal medya paylaşımlarından çok, anabalarının kendileriyle ilgili paylaşım yapmalarına daha katı yaklaşmaktadırlar. Ancak görünen o ki bu konuda gençlerin sesi yeterince anababalar tarafından duyulmamaktadır (De Wolf, 2020). Belçika'da, 13-16 yaş aralı̆̆ında 817 ergenle gerçekleştirilen bir çalışmada, anababaların çocuklarıyla ilgili paylaşımlarının alt metninin, ergenlerin bu paylaşımlara yönelik tutumu üzerinde etkili olduğu bulunmuştur (Versvijvel ve diğ., 2019). Bulgular, ergenlerin anababaların kendi imajlarını yönetme amacıyla yapılan ergen çocukları ile ilgili sosyal medya paylaşımlarına karşı olumlu bir tutum sergilemezken, çocuklarıyla ilgili özel anları bilgi amaçlı arşivleme amacıyla yapılan paylaşımlara karşı daha olumlu bir tutum içerisinde olduklarını ortaya koymuştur. Ancak ergenler genel olarak bu tür paylaşımlara sıcak bakmamakta; özellikle mahremiyetine daha çok önem veren ergenler anababaların bu tür paylaşımlarını onaylamamaktadır (Versvijvel ve diğ., 2019). Ergenlerin söz konusu tutumları, bağımsızlık çabalarının yoğunlaştığı ve özerklik kazanmaya çalışarak bireyselleşmeye çalıştıkları gelişimsel bir dönemde olmalarıyla bağlantılı olabilir (Özdemir ve Çok, 2011).

Diğer yandan, anababaların ergenlik dönemindeki çocukları hakkında sosyal medyada yaptıkları paylaşımlarla ilgili, 12-14 yaş aralığındaki ergenlerin tutumlarına yönelik yapılan odak grup çalışmasında, ergenlerin çoğu bu paylaşımları onayladıklarını ve anababalarına güvendiklerini belirtse de bu tür uygulamaların, bazı paylaşımları utanç verici bulmaları nedeniyle ergenlerde öfkeye yol açtı̆̆ belirtilmiştir. Katılımcılar, anababaların bu konuda daha duyarlı ve seçici olmaları gerektiğinin yanı sıra kendilerinden izin almalarını ve bazı sınılara daha saygı1ı yaklaşmaları gerektiğini vurgulamışlardır (Ouvrein ve Verswijvel, 2019). Bu noktada, anababaların söz konusu öğeleri göz önünde bulundurmalarının, hem kimlik ve özerklik gelişimi açısından duyarlı dönemindeki ergen çocuklarıyla olan ilişkileri hem de çocuklarının bireyselleşmeleri sürecinde destek olmaları açısından önem taşımaktadır.

\section{Sonuç ve Öneriler}

Çocukla ilgili sosyal medya paylaşımları onun gelecekteki kimliğini ve nasıl anılacağını belirleme gücüne sahiptir (Hasanah, 2019). Anababalar bir gün çocuklarıyla sosyal medyada yaptıkları paylaşımlarla ilgili yüz yüze geleceklerdir. Her ne kadar anababalar izleyiciler ile kendileri arasına sınır çizdiklerini varsaysalar da paylaşımların izleyicilerin çok ötesinde yayılma olasılığının olduğu dikkate alınmalıdır. Silinen paylaşımların silinme öncesi başka bir kullanıcı tarafından kayıt altına alınmış olabileceği ve sosyal medya hesaplarından tamamen silinmeme riski göz önünde bulundurularak paylaşım yapılma(ma)sı çocuk hakları ve güvenliği 
açısından daha bilinçli bir sürece kaynaklık edecektir (Steinberg, 2017). Silinen gönderilerin uzun bir süre hafızada kaldığı gerçeği gözden kaçabilmektedir. Anababanın çocuğuyla ilgili komik ve/veya utanç verici durumlarını paylaşması, çocuğun arkadaşları tarafından yıllar sonra bile kasıtlı olarak alay konusu olmasına hatta bu eski paylaşımların zorbalık amacıyla yayılmasına neden olabilir. $\mathrm{Bu}$ tür paylaşımların çocuğun psikolojisi üzerinde yapabileceği tüm etkileri göz önünde bulundurulmalı ve çocuğun duygularının farkında olunmalıdır (Çimke ve diğ., 2018). Diğer yandan çocuklar anababalarından gördükleri üzere özel yaşamlarıyla ilgili gönderilerin sosyal medyada yer almasını doğal karşılayacak ve normalleştirecektir. $\mathrm{Bu}$ durum özel yaşamın mahremiyetine ters düşmektedir. Anababaların model olma sorumluluğu açısından da konu önemlidir.

Anababaların çocuklarıyla ilgili fotoğraf ve videolarını sosyal medyada paylaşımları gelişmekte olan bir çalışma alanıdır. Söz konusu paylaşımların, kültürel bağlamda incelenmesi, sharenting olgusunun daha bütünsel anlaşılması için yararlı olabilir. Yapılan çalışmalar sınırlı olsa da anababaların sosyal medyada çocuklarıyla ilgili paylaşımlarının, istismar, kötüye kullanma ve çocuk hakları açısından dikkate değer bir duruma dönüştüğünü ortaya koymaktadır. Bu konuda farkındalığın artırılması hem öğretmenler ve tüm eğitimciler hem de anababalar açısından önemlidir. Özellikle çocuk haklarının giderek artan şekilde önem kazandığ günümüzde konunun akademik alanda ve uygulamalarda daha çok ele alınması ümit edilmektedir.

Sosyal medya paylaşımlarıyla başka anababalardan gelecek olan öneri, arkadaşlar ve akrabalarla bağlantı halinde olma isteği ve başka nedenlerin anababaların çocuklarıyla ilgili paylaşım yapmaları konusunda güdülenme yarattığına daha önce değinilmişti (Bessant, 2018). Çocukların kimlikleri belli edilmediği sürece yapılan paylaşımlarda risk ve olumsuzluk istismar ve çocuk hakları açısından görece azdır. Çocukları görüntülerken arkalarına geçerek fotoğraflamak ve sırtlarından görüntü almak veya yüzlerinin göründüğü durumlarda yüzlerini sansürlemek izlenmesi gereken doğru yollardır. Diğer yandan yapılan paylaşımlarda çocuk hakkında pek çok bilginin verilmesi öngörülmeyen tehlikelere yol açabileceği için çocuğun devam ettiği okul, bağlı olduğu kuruluşlar ve benzeri bilgilerin paylaşılmaması da öneriler arasındadır.

Anababaların çocukları ile ilgili yaptıkları paylaşımların sonuçları büyük ölçüde ileride onların gençlik ve yetişkinlik çağında ortaya çıkacaktır. Google CEO'su Eric Schmidt'e göre, gelecekte herkesin mutlaka utanacağı görüntülerinin veya hikâyelerinin olacağı ve çocukluk ve gençlik çağında bugün yapılan paylaşımların zaman geçtikçe pek çok kişiyi kimliğini değiştirmenin eşiğine getirme olasılığının olduğu öngörülmektedir (Steinberg, 2017). Henüz çocukları dijital dünyaya kişisel olarak giriş yapmadan önce anababalar, çocukları ile ilgili paylaşımlar yaparak onların dijital kimliklerini oluşturmaktadırlar. Çocukların henüz küçükken tüm çocukluklarının sosyal medyada belgelenmesi ve herkese açık olarak paylaşılması gerçeği karşısında ne hissedeceklerinin dikkate alınması önemlidir (Prakash, 2019). 
Çocukların ve gençlerin sosyal medyada yer almalarında onların korunmalarına odaklanılmışken diğer yandan anababaların çocuklarıyla ilgili yaptıkları paylaşımlarla onların güvenliğini ne kadar tehlikeye attıkları konusu gündeme getirilmelidir (Donovan, 2020). Buradaki önemli nokta konuya ilişkin yasal ve resmi düzenlemelerin ve anababaların konuya ilişkin farkındalıklarının eksikliğidir. $\mathrm{Bu}$ nedenle anababaların bilinçli sosyal medya kullanıcıları olmalarına yönelik eğitimler verilmelidir. Bu konuda Aile, Çalışma ve Sosyal Hizmetler Bakanlığı, sivil toplum kuruluşları ve üniversitelerin işbirliği içinde olmasının önem taşıdığı düşünülmektedir. Söz konusu kurumlar öncülügü̈nde, çocukların fotoğraf ve videolarının sosyal medyada olası tehlikeleri göz önünde bulundurarak paylaşımları nasıl yapmaları gerektiği konusunda eğitimler verilerek öğretmenlerin ve ailelerin bilinçlenmeleri sağlanabilir. Buna ek olarak, 2021 y1lı itibariyle yenilenmesi öngörülen eğitim fakültesi öğretmen yetiştirme programlarına, çocuk hakları ve etik gibi derslerin eklenerek içeriklerine sosyal medyada paylaşım yapma konusuna ilişkin kazanımlar eklenebilir. Topluma hizmet dersleri kapsamında anababaların çocuklarının fotoğraf ve videolarını sosyal medyada paylaşmaları konusunda bilinçlendirmeye yönelik uygulama çalışmaları yapılabilir.

Anababalar bu paylaşımların, çocukları üzerinde olumsuz etkilere neden olmaması için paylaştıkları içeriğe dikkat etmelidir. Anababaların bu paylaşımları yapmadan önce dikkat etmesi gereken başlıca öğeler arasında; halka açık olarak paylaşılamayacak hiçbir bilginin çevrimiçi paylaşılmaması, aile içi paylaşımlar yapılacaksa mutlaka sosyal medya ortamının güvenlik ayarlarından gerekli gizlilik kısıtlamalarının yapılması, anababaların özellikle arama motorlarında çocuklarının adı aratıldığında bildirim gelecek şekilde ayarlar yapması, çocuklarının sağlık sorunları ya da başka rahatsızlıklarını paylaşacaklarsa anonim olarak paylaşılması, çocuklarının gerçek isimleri ya da yerleri paylaşılacaksa bununla ilgili uyarılar yapılması, anababaların çocuklarına yapılacak paylaşımlar ile ilgili veto yetkisini vermesi, anababaların herhangi bir şekilde çocuklarının kıyafetsiz görüntülerini paylaşmaması ve yapılan paylaşımların çocuklarının bugün ve gelecek yaşamlarını etkileyebileceğinin farkında olması şeklinde sıralanabilir (Otero, 2017). Giderek artan ölçüde anababaların bu bilimsel önerilere dikkat etmeleri, çocukların hem güvenliği hem de hakları açısından daha sağlıklı bir gelişime öncülük edecektir.

\section{Etik Kurul Kararı}

$\mathrm{Bu}$ araştırma, derleme türünde bir çalışma olduğundan etik kurul kararı gerektirmemektedir.

\section{Kaynakça}

Abidin, C. (2015). Micro-microcelebrity: Branding babies on the internet. $M / C$ Journal, 18(5), 1-13. https://doi.org/10.5204/mcj.1022 
Akpınar, B. S., Paylan, N., Etlik, Ş., Erus, B. ve Karakoç, H. (2020). "Sharenting" konusunda ebeveynlerin farkındalık düzeyleri. Necmettin Erbakan Üniversitesi Genel Sağllk Bilimleri Dergisi, 2(2), 8-18. https://dergipark.org.tr/en/download/article-file/958817

Albayrak, K. (2019). Dijital ortamda benlik sunumları üzerine niteliksel bir araştırma [Yayımlanmamış yüksek lisans tezi]. İstanbul Üniversitesi.

Altun, D. (2019). An investigation of preschool children's digital footprints and screen times, and of parents' sharenting and digital parenting roles. International Journal of Eurasia Social Sciences, 10(35), 76-97. http://www.ijoess.com/Makaleler/147332736_5.\%207697\%20dilek\%20altun.pdf

Archer, C., and Kao, K. T. (2018). Mother, baby and Facebook makes three: Does social media provide social support for new mothers? Media International Australia, 168(1), 122-139. https://doi.org/10.1177/1329878X18783016

Aslan, S. ve Durmuş, E. (2020). Okul öncesi dönemde güncel bir ebeveyn davranıș1: Sharenting. Erken Çocukluk Çalışmalarl Dergisi, 4(1), 135-151. https://doi.org/10.24130/eccd-jecs.1967202041185

Avrupa Konseyi. (1950). Avrupa insan hakları sözleşmesi: 11. ve 14. protokoller ile değiştirilen metin. http://www.echr.coe.int/Documents/Convention_TUR.pdf

Başoğlu, R. (2020). Annelerin sosyal medya kullanımı ve Instagramda olan popüler anneler. Akademik Tarih ve Düşünce Dergisi, 7(1), 857-873. https://dergipark.org.tr/tr/download/article-file/1097437

Benevento, A. (2018). Parents frame childhood for the world to see in digital media postings [Doctoral dissertation, City University of New York]. The Graduate Center. https://academicworks.cuny.edu/gc_etds/2905

Bessant, C. (2018). Sharenting: Balancing conflicting rights of parents and children. Journal of Computer, Media and Telecommunication Law, 23(1), 1-3. https://researchportal.northumbria.ac.uk/en/publications/sharenting-balancingthe-conflicting-rights-of-parents-and-childr

Birleşmiş Milletler Çocuklara Yardım Fonu. (1989). Birleşmiş milletler çocuk haklarına dair sözleşme. https://www.unicef.org/turkey/\%C3\%A7ocukhaklar\%C4\%B1na-dair-s\%C3\%B6zle\%C5\%9Fme

Brosch, A. (2016). When the child is born into the internet: Sharenting as a growing trend among parents on Facebook. New Educational Review, 43(1), 225-235. https://doi.org/10.15804/tner.2016.43.1.19

Brosch, A. (2019). Children's rights in digital environment-cultural and geographical contexts across Europe and Africa. The New Educational Review, 56(2), 215229. https://tner.polsl.pl/e56/a18.pdf 
Cino, D., and Dalledonne-Vandini, C. (2020). "My kid, my rule": Governing children's digital footprints as a source of dialectical tensions between mothers and daughters-in-law. Studies in Communication Sciences, 1-22. https://doi.org/10.24434/j.scoms.2020.02.003

Coughlan, T., and Lister, K. (2018, April). The accessibility of administrative processes: Assessing the impacts on students in higher education. Proceedings of the 15th International cross-disciplinary conference on web accessibility. https://doi.org/10.1145/3192714.3192820

Çimke, S., Yıldırım-Gürkan, D. ve Polat, S. (2018). Sosyal medyada çocuk hakkı ihlali: Sharenting. Güncel Pediatri, 16(2), 261-267. https://dergipark.org.tr/tr/download/article-file/518497

De Wolf, R. (2020). Contextualizing how teens manage personal and interpersonal privacy on social media. New media \& society, 22(6) 1058-1075. https://doi.org/10.1177/1461444819876570

Donovan, S. (2020) Sharenting: The forgotten children of the GDPR. Peace Human Rights Governance, 4(1), 35-59. https://doi.org/10.14658/pupj-phrg-2020-1-2

Doty, J., and Dworkin, J. (2014). Parents' of adolescents use of social networking sites. Computers in Human Behavior, 33, 349-355. https://doi.org/10.1016/j.chb.2013.07.012

Dönmez, D. (2019). Yeni nesil ebeveynlik ve sosyal medya bağlamında blogger anneler [Yayınlanmamış yüksek lisans tezi]. İstanbul Üniversitesi.

Duggan, M., Lenhart, A., Lampe, C., and Ellison, N. (2015). Parents and social media: Mothers are especially likely to give and receive support on social media. https://www.pewresearch.org/internet/2015/07/16/parents-and-social-media/

Erişir, R. ve Erişir, D. (2018). Yeni medya ve çocuk: Instagram özelinde "sharenting" "paylaşanababalı" örneği. Yeni Medya, (4), 50-64. https://dergipark.org.tr/tr/pub/yenimedya/issue/55568/760577

Gibson, L., and Hanson, V.L. (2013, April). Digital motherhood: How does technology help new mothers? Proceedings of the SIGCHI Conference on Human Factors in Computing Systems. https://doi.org/10.1145/2470654.2470700

Günüç, S. (2020). Sharenting eyleminin psikolojik açıdan değerlendirilmesi: Türk ve İngiliz annelerinin karşılaştırılması. Psikiyatride Güncel Yaklaşımlar, 12, 281297. https://doi.org/10.18863/pgy.795651

Haley, K. (2020). Sharenting and the (potential) right to be forgotten. Indiana Law Journal: 95(3). https://www.repository.law.indiana.edu/ilj/vol95/iss3/9 
Hasanah, F. F. (2019). Sharenting in the perspective of Islamic education. International Journal on Islamic Educational Research, 3(2), 42-50. https://doi.org/10.14421/skijier.2019.2019.33.05

Hessel, H., He, Y., and Dworkin, J. (2017). Paternal monitoring: The relationship between online and in-person solicitation and youth outcomes. Journal of Youth and Adolescence, 46(2), 288-299. https://doi.org/10.1007/s10964-016-0490-6

Humphreys, L. (2018). The qualified self: Social media and the accounting of everyday life. MIT Press.

İnan-Kaya, G. ve Kaya, U. (2017). Bir ebeveyn pratiği olarak "sharenting”. N. O. Akfirat, D. F. Staub ve G. Yavaş (Ed.), Current debates in education içinde (ss. 443-456). Ijopec.

Kopecky, K., Szotkowski, R., Aznar-Díaz, I., and Romero-Rodríguez, J.-M. (2020). The phenomenon of sharenting and its risks in the online environment. Experiences from Czech Republic and Spain. Children and Youth Services Review, 110(1), 93-103. https://doi.org/10.1016/j.childyouth.2020.104812

Kumar, P. C., Chetty, M., Clegg, T. L., and Vitak, J. (2019). Privacy and security considerations for digital technology use in elementary schools. In S. Brewster, G. Fizpatrick, A. Cox, and V. Kostakos (Eds.), Proceedings of the 2019 CHI conference on human factors in computing systems-CHI '19 (pp. 1-13). Association for Computing Machinery Press.

Kurt, S. (2016). Çocuk haklarına ilişkin temel uluslararası belgeler ve Türkiye uygulaması. Sosyal Politika Çalışmaları Dergisi, 16(36), 99-127. https://doi.org/10.21560/spcd.28915

Latipah, E., Kistoro H. C. A, Hasanah, F.F., and Putranta, H. (2020). Elaborating motive and psychological impact of sharenting in millennial parents. Universal Journal of Educational Research, 8(10), 4807-4817. https://doi.org/10.13189/ujer.2020.081052

Lazard, L., Capdevila, R., Dann, C., Locke, A., and Roper, S. (2019). Sharenting: Pride, affect and the day-to-day politics of digital mothering. Social and $\begin{array}{llll}\text { Personality } \quad \text { Psychology } & \text { Compass, } & \text { 13(4), }\end{array}$ https://doi.org/10.1111/spc3.12443

Levy, E. (2017). Parenting in the digital age: How are we doing? https://parentzone.org.uk/sites/default/files/Parenting\%20in\%20the\%20Digital $\% 20$ Age $\% 20$ conference\%20report.pdf

Lipu, M., and Siibak, A. (2019). “Take it down!”: Estonian parents' and pre-teens' opinions and experiences with sharenting. Media International Australia, 170(1), 57-67. https://doi.org/10.1177/1329878X19828366 
Lumsden, L. (2014). Mothers, beware: Instagram users are stealing baby pictures and creating elaborate, sinister role-playing scenarios with the images. https://www.dailymail.co.uk/femail/article-2766981/Mothers-bewareInstagram-users-stealing-baby-pictures-creating-elaborate-sinister-roleplaying-scenarios-images.html

Lynch, N., and Liefaard, T. (2020). What is left in the "too hard basket"? Developments and challenges for the rights of children in conflict with the law. International Journal of Children's Rights, 28, 89-110. https://doi.org/10.1163/15718182-02801007

Maraşlı, M., Er, S., Yılmaztürk, N. H., and Çok, F. (2016). Parents’ shares on social networking sites about their children: Sharenting. Anthropologist, 24(2), 399406. https://doi.org/10.1080/09720073.2016.11892031

Milli Eğitim Bakanlığı. (2017). Okullarda sosyal medya kullanımı 2017/12 genelge. https://drive.google.com/file/d/0BxCYXmeNe_fFSzJTNVc4MkRJUDA/view

Morse, J. (2019). So it's come to this: An unborn baby 'kidfluencer' has 112,000 Instagram followers. https://mashable.com/article/unborn-kidfluencer/

Moser, C., Chen T., and Schoenebeck, S. Y. (2017, May). Parents' and children's preferences about parents sharing about children on social media. Proceedings of the 2017 CHI Conference on Human Factors in Computing Systems. https://doi.org/10.1145/3025453.3025587

Nalbantoğlu, S. (2018). Bir temel hak olarak unutulma hakk1. Türkiye Adalet Akademisi Dergisi, (35), 583-605. https://dergipark.org.tr/tr/download/articlefile/980809

Oswald, M., James, H., and Nottingham, E. (2016). The not-so-secret life of five-yearolds: Legal and ethical issues relating to disclosure of information and the depiction of children on broadcast and social media. Journal of Media Law, 8(2), 198-228. https://doi.org/10.1080/17577632.2016.1239942

Otero, P. (2017) Sharenting... Should children's lives be disclosed on social media? Arch Argentina Pediatr,115(5), 412-413. https://doi.org/10.5546/aap.2017.eng.412

Ouvrein, G., and Verswijvel, K. (2019). Sharenting: Parental adoration or public humiliation? A focus group study on adolescents' experiences with sharenting against the background of their own impression management. Children and $\begin{array}{llll}\text { Youth Services } & \text { Review, } & \text { 319-327. }\end{array}$ https://doi.org/10.1016/j.childyouth.2019.02.011

Özdemir, Y. ve Çok, F. (2011). Ergenlikte özerklik gelişimi. Türk Psikolojik Danışma ve Rehberlik Dergisi, 4(36), 152-164. https://www.pegem.net/dosyalar/dokuman/138846-2014012592917-5.pdf 
Prakash, A. (2019). Parental role in creation and preservation of digital identity of children. Test Engineering \& Management, 81, 4907-4911. https://papers.ssrn.com/sol3/papers.cfm?abstract_id=3521688

Sarkadi, A., Dahlberg, A., Fängström, K., and Warner G. (2020). Children want parents to ask for permission before "sharenting". Journal of Paediatric Child Health, 56(6), 981-983. https://doi.org/10.1111/jpc.14945

Schroeder, A. (2020). The horrifying, abusive world of baby roleplaying on Instagram. https://www.dailydot.com/irl/instagram-baby-roleplaying-rpfinding/

Serin, H. (2019). Sosyal medyada çocuk hakları ihlalleri: Ebeveynler ve öğretmenler farkında mi? Eskişehir Osmangazi Üniversitesi Sosyal Bilimler Dergisi, 20, 1005-1031. https://doi.org/10.17494/ogusbd.555107

Siibak, A. (2019). Educating 21st century children: Emotional well-being in the digital age. Paris: Educational Research and Innovation, OECD Publishing. https://doi.org/10.1787/b7f33425-en

Steinberg, S. B. (2017). "Sharenting: Children's privacy in the age of social”, UF Law Scholarship Repository, Emory Law Journal, 66(83), 839-884. https://scholarship.law.ufl.edu/cgi/viewcontent.cgi?article=1796\&context=facu ltypub

Sukk, M., and Soo, K. (2018). Preliminary findings of the EU kids online 2018 Estonian

survey. https://sisu.ut.ee/sites/default/files/euko/files/eu_kids_online_2018_estonia_su mmary.pdf

Sullivan, G. (2019). Baby role-play: A potentially abusive fetish flourishing on Instagram. https://www.washingtonpost.com/news/morningmix/wp/2014/09/24/baby-role-play-a-potentially-abusive-fetish-flourishing-oninstagram/

Turgut, Y. E., Kopuz, T., Aslan, A., and Eryılmaz-Toksoy, S. (2021). Factors affecting parents' share on social media about their children. Çukurova Üniversitesi Eğitim Fakültesi Dergisi, 50(1), 276-292.

Türk Ceza Kanunu (5237 NK, 26.09.2004). Resmi Gazete, 25611, 12.10.2004. https://www.resmigazete.gov.tr/eskiler/2004/10/20041012.htm\#1

Türkiye Büyük Millet Meclisi. (2016). Çocuk Haklarına Dair Sözleşme’nin bildirim usulüne ilişkin ihtiyari protokol. https://www2.tbmm.gov.tr/d26/1/1-0322.pdf

Versvijvel, K., Walrave, K. Hardies, K., and Heirman, W. (2019). Sharenting, is it a good or a bad thing? Understanding how adolescents think and feel about sharenting on social network sites. Children and Youth Services Review, 104, 110. https://doi.org/10.1016/j.childyouth.2019.104401 
Whigham, N. (2015). Digital kidnapping will make you think twice about what you post to social media. www.news.com.au/lifestyle/real-life/wtf/digitalkidnapping-will-make-you-think-twice-about-what-you-post-to-socialmedia/news-story/4dc1c9a22b657f090c25c9393f66fe 88

Zuckerberg, M. (2020). Mark Zuckerberg unveils Facebook timeline. http://www.youtube.com/watch?v=v67PFmVvqDs 


\title{
Parents' Shares about Their Children on Social Media
}

\begin{tabular}{cccc}
\hline ARTICLE TYPE & Received Date & Accepted Date & Published Date \\
Review Article & 11.18 .2020 & 08.11 .2021 & 08.26 .2021 \\
\hline
\end{tabular}

\section{Tuba Özgül (iD) ${ }^{1}$, Sühendan Er (iD) ${ }^{2}$ and N. Hazal Yılmaztürk (iD ${ }^{3}$ \\ TED University}

Figen Çok (iD ${ }^{4}$

Başkent University

\begin{abstract}
Social media is increasingly emerging as environments where more and more people are involved. The limited knowledge of parents' sharing about their children on social media (sharenting), which is a new concept in the world and in Turkey, has been compiled in this study. In the study, the information, photos, or videos of the children shared by parents on social media and the possible reasons for these shares are discussed in a way that includes the phenomenon of reflecting feelings, thoughts and behaviors towards others. Based on the examples in which sharenting starts before the birth of the child, it was emphasized what parents should be careful of while sharing and the responsibilities they should fulfill in terms of sharing. In addition, concepts such as digital footprint and digital abduction were explained, and the drawbacks of the issue in terms of both developmental and children's rights for children and adolescents were discussed. Finally, suggestions were presented on what can be done to raise parents' awareness towards possible dangers while sharing their children on social media.
\end{abstract}

Keywords: Parents, children, children's rights, adolescents, social media sharing.

Ethics committee approval: Since this study is a review article, it does not require an ethics committee decision.

\footnotetext{
${ }^{1}$ Corresponding Author: Res. Assist., Faculty of Education, Department Elemantary Education, Early Childhood Education Program, e-mail: tuba.ozgul@ tedu.edu.tr, https://orcid.org/0000-0002-7728-4334

${ }^{2}$ Assoc. Prof., Faculty of Education, Department Elemantary Education, Early Childhood Education Program, e-mail: suhendan.er@tedu.edu.tr, https://orcid.org/0000-0002-0317-2356

${ }^{3}$ Res. Assist., Faculty of Education, Department of Educational Sciences, Psychological Counseling and Guidance Program, e-mail: hazal.yilmazturk@tedu.edu.tr, https://orcid.org/0000-0002-8500-518X

${ }^{4}$ Prof., Faculty of Education, Department of Educational Sciences, Psychological Counseling and Guidance Program, email: figencok@baskent.edu.tr, https://orcid.org/0000-0003-2406-1345
} 


\section{Purpose and Significance}

Social media posts, which are a communication tool, have created great effects on people and led to the emergence of new concepts within the scope of scientific studies. Among the concepts of social media sharenting, that is, the concept of sharing and parenting in English has been put forward to draw attention to parents' sharing of their children of all ages in more and more detail.

Parents who are in an effort to keep up with the rapid advances in technology start to archive the information about their children from the pregnancy period to the birth of their children, their growth, development, education, and other significant moments (Altun, 2019).

Parents' posts on social media are important in terms of both sharing and learning from these sharings. Yet, privacy, well-being and legal notions of sharenting gain importance within the spread of power and frequency of social media usage of parents (Brosch, 2019).

\section{Parents' Motivations for Sharenting}

In various studies, there are explanations about why or with what motivation parents share their children on social media. Self-presentation, communication, social support, parenting experience, and archiving can be claimed as a motivation of sharenting.

Self-presentation. According to Goffman's Self-Presentation Theory (1959), the desire to create an impression on the opposite side is very important. The moment the individual interacts with others, (s)he actually gets on the stage in front of the other and interacts on this stage by conveying some things and not conveying some things or by covering some things, in other words, (s)he exhibits the play (as cited in Albayrak, 2019). In this context, parents' mostly positive posts on the social media platform (Maraşlı et al., 2016) can be considered within the framework of exhibiting the patterns they want to convey.

Communication. Another motivation for sharenting for parents is that they prefer social media to communicate more often than using tools such as books, texting, or Skype in order to communicate (Doty and Dworkin, 2014). Besides, in adolescence, the decrease in the behavior of individuals to open themselves to their parents directs parents to maintain communication with their children regarding social media and sharenting (Hessel et al., 2017).

Social support and parenting experience. For mothers who have just given birth, it can be important to gain self-efficacy as a mother and to gain platforms for their new roles using the technology channel. The comments to the posts motivate the parents for new experiences, as well as provide the basis for meeting their needs of being liked by their children (Latipah et al., 2020). 
Archiving. It is known that parents not only store the memories of their children through social media but also record the motor and psychosocial developments of their children with photos and videos and to follow and evaluate their suitability to their developmental period (Latipah et al., 2020).

\section{From Parents' Sharing About Their Children on Social Media to Become an Influencer}

Today, social media influencers, which attract attention with their various features, appear as a social phenomenon. Influencers can be involved in television programs to exhibit their skills in various fields such as commentary, singing, gourmet and fashion (Benevento, 2018).

As an example of this phenomenon, the Instagram account and hashtag with the name of fashionkids, which has around 3.5 million followers around the world today, defines itself as the platform of inspiring parents who carefully construct children's fashion, design and lifestyle from all over the world (Benevento, 2018). Parents share photos and images of stylish children between the ages of 0-6 and there is also a sales target in this account (Erişir and Erişir, 2018).

\section{Evaluation of Parents' Sharing Their Children on Social Media in Terms of Children's Rights}

Parents significantly ignore children's rights determined by international conventions and laws, with their posts (Lynch and Liefaard, 2020). Children's rights in the United Nations Convention on the Rights of the Child and the European Convention on Human Rights revealed that there is a contradiction of parental sharing (Benevento, 2018).

The rights of children are also prominent in the Turkish Penal Code. In Turkey, a mother who shared children on social media has been prevented in order to protect children's privacy rights (Dönmez, 2019).

It has been observed that children who become aware of the posts about themselves as they grow up are often dissatisfied with their parents' sharing themselves in naked, embarrassing situations (Haley, 2020). In recent years, the issue of the right to be forgotten, which is proposed as a new fundamental right, has become important with the increase of lawsuits regarding internet posts. The right to be forgotten is defined as the right of the individual to request that no document or photograph be included in the online platforms and to request their deletion (Nalbantoğlu, 2018).

\section{Digital Footprint and Digital Kidnapping}

Parents' posts about their children are explained as determining the footprint of the child in the digital environment. Virtual footprints are started forming with parents' sharings about children's personal information on the internet from the moment children are born (Cino and Dalledonne-Vandini, 2020). 
Digital kidnapping is when a stranger steals a child's images from social media and uses this child's identity or image with different fictions (Kopecky et al., 2020). Sharing the address of the place where the child lives and the school he/she attends, sharing the face of the child, sharing the birthday through social media posts create a potential digital kidnapping environment for children (Whigham, 2015).

\section{Digital Kidnapping Sample: 'Baby Role Play'}

People can pretend to be a famous person, behave like her/him, and introduce themselves to other people as a famous person and even make discourses on her/his behalf. Being present on social media with such different identities is called role-play. Players can think of other people's children as their own children and share as if they were their own parents. This case, which is referred to as virtual adoption in the literature, is a clear example of digital kidnapping (Sullivan, 2019).

Even though the issue comes up with hashtags such as \#stopstealingpics, \#stopbabyroleplay, \#stopbabyrp, parents continue to share their children's photos and videos on social media and ignore the privacy and safety of their children without being aware of the possible harms of digital kidnapping (Lumsden, 2014).

\section{Adolescents}

The adolescents stated that they do not like sharing their photos on social media, taking unauthorized photos and writing about them on social media, respectively. Children and adolescents want their parents to be asked and their views are taken into account before posting on social media. In a study, 12-16 years old adolescents stated that their parents did not respect their privacy, and share their embarrassing, strange, behaved strangely, or shared naked images on social media (Levy, 2017).

While adolescents do not display a positive attitude towards the social media posts of parents about their adolescent children, which are made for the purpose of managing their own images, they have a more positive attitude towards the posts made for the purpose of archiving special moments about their children for informational purposes. Given attitudes of adolescents may be related to their being in a developmental period in which their independence efforts are intense and they try to become individualized by trying to gain autonomy (Özdemir and Çok, 2011).

\section{Recommendations for Parents}

The suggestions for parents regarding sharenting might be listed as not to share any information that cannot be shared publicly online, to make the necessary privacy restrictions in the security settings of the social media environment if domestic sharing is to be made, to make settings for parents to receive notification when their children are searched on search engines, anonymous if they share health problems or other ailments of their children If the real names or places of their children are to be shared, warnings about it, parents give veto power to their children about the shares to be made, parents do not share their children without clothes in any way, and they are aware that the posts can affect their children's today and future lives (Otero, 2017). 


\section{Conclusion}

Social media posts about the child have the potential to determine their future identity and how they will be remembered (Hasanah, 2019). Considering that the deleted posts may have been recorded by another user before the deletion and the risk of not being completely deleted from social media accounts, (un)sharing will be the source of a more conscious process in terms of children's rights and safety (Steinberg, 2017).

Parents should consider all the effects of their posts about their children on the psychology of the children and be aware of the children's feelings. The issue is also important in terms of the responsibility of parents as role models.

Limited studies show that the issue of parents sharing about their children on social media has turned into a very remarkable situation in terms of abuse and children's rights. Raising awareness on this issue is important for educators, researchers and parents.

\section{Ethical Committee Approval}

Since this research is a review article, it does not require an ethics committee decision. 